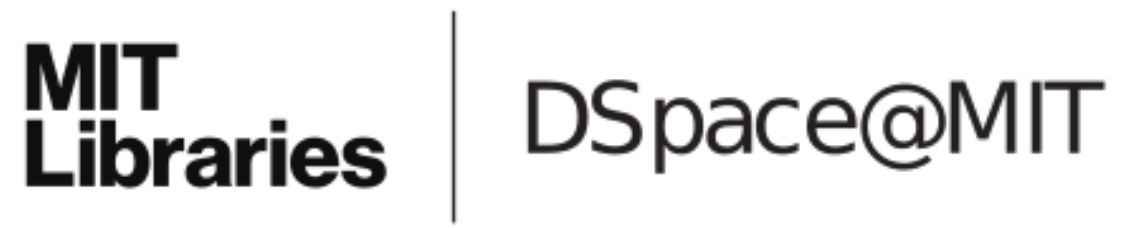

\author{
MIT Open Access Articles
}

\section{Real-time biocatalyst loading and electron transfer via microfabricated transparent electrode}

The MIT Faculty has made this article openly available. Please share how this access benefits you. Your story matters.

Citation: Parra, E.A. et al. “Real-time biocatalyst loading and electron transfer via microfabricated transparent electrode." Micro Electro Mechanical Systems (MEMS), 2010 IEEE 23rd International Conference on. 2010.1183-1186. (c) 2010, IEEE

As Published: http://dx.doi.org/10.1109/MEMSYS.2010.5442423

Publisher: Institute of Electrical and Electronics Engineers

Persistent URL: http://hdl.handle.net/1721.1/61633

Version: Final published version: final published article, as it appeared in a journal, conference proceedings, or other formally published context

Terms of Use: Article is made available in accordance with the publisher's policy and may be subject to US copyright law. Please refer to the publisher's site for terms of use. 


\title{
REAL-TIME BIOCATALYST LOADING AND ELECTRON TRANSFER VIA MICROFABRICATED TRANSPARENT ELECTRODE
}

\author{
Erika A. Parra ${ }^{1}$, Adrienne Higa ${ }^{1}$, Cullen R. Buie ${ }^{1, *}$, John D. Coates ${ }^{2}$, Liwei Lin ${ }^{1}$ \\ ${ }^{1}$ Berkeley Sensor and Actuator Center, University of California \\ ${ }^{2}$ Plant and Microbial Biology, University of California \\ *Present Affiliation: Department of Mechanical Engineering, MIT
}

\begin{abstract}
Real-time and simultaneous measurements of bacterial catalyst loading and electron transfer have been accomplished via a microfabricated transparent electrode within the setup of a micro- microbial fuel cell $(\mu \mathrm{MFC})$. By characterizing the electron transfer on a per cell basis, we aim to generate a methodology for species-to-species comparison and formulate a baseline for electrode optimizations. This is critical and fundamental knowledge to be explored within the scope of MFCs as power devices with direct implications to molecular cell biology. Preliminary results are presented showing that, using Geobacter sulfurreducens, a signal to noise ratio (SNR) of 11 can be achieved upon inoculation and single cells can be non-invasively and accurately identified using intrinsic fluorescence.
\end{abstract}

\section{INTRODUCTION}

With an upper bound of $3 \mathrm{~W} / \mathrm{cm}^{3}$ for prokaryote energy conversion [1], electrical energy harvesting from metabolism is a promising research area encompassing potential applications ranging from bioremediation to portable electronics. As illustrated by Figure 1, the concept consists of using microorganisms' as bio-catalysts within electrochemical cells to break down organics into electrons and protons. Previous works have demonstrated $0.12 \mu \mathrm{W} / \mathrm{mm}^{2}$ from $\mu \mathrm{MFCs}$, using the exoelectrogenic bacterium $G$. sulfurreducens [2-5]. However, the specific metabolic activity of microorganisms and their electron discharge characteristics from biofilms have been difficult to characterize. Specifically, challenges come from uneven bacterial coverage on large anode electrodes and the complexity of the biofilm formation within closed microbial fuel cell systems as illustrated by Figure 2. Because of these constraints, evaluating species for power applications has remained controversial. Utilizing a bottom-up approach, we present a device designed to characterize bacterial electron transfer on a per cell basis. By developing a microscopy compatible $\mu \mathrm{MFC}$, continuous monitoring of bacterial loading of micro-electrodes and electrical signal can be measured in real-time. We also seek to answer questions regarding metabolic activity of microorganisms far from the electrode and the electron discharge characteristics through biofilms using fluorescence microscopy.

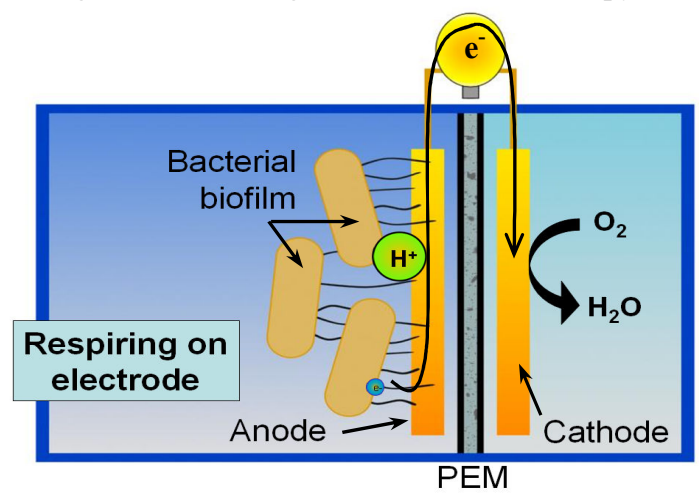

Figure 1. Schematic illustrating energy harvesting from microbial catalysis through an electrochemical cell. Bacterium catalyze organics into protons and electrons. The latter are transferred to an electrode through intrinsic metabolic processes.
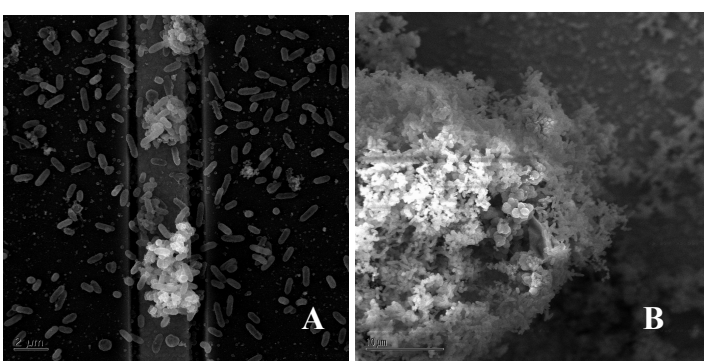

Figure 2. Electron micrographs illustrating complexity of microbial biofilms on electrodes. G. sulfurreducens is approximately $2 \mu \mathrm{m} \times 300 \mathrm{~nm}$ and grows biofilms roughly $40 \mu \mathrm{m}$ thick. (A) Cellular clusters on patterned gold electrode. (B) Mature biofilm on gold wire.

\section{DESIGN AND FABRICATION}

The $\mu$ MFC geometry and materials were selected to satisfy a number of constraints. Specifically, these included: (i) high transmissivity in the UV-VIS (Ultraviolet and Visible) range to allow for transmitted light and fluorescent microscopy, (ii) flow-through anodic and cathodic chambers for insitu washing and electrolyte replenishment, and (iii) anaerobic anodic chamber conditions. 


\section{Electrodes}

Figure 3 shows the schematics for the top and cross sectional views of the device. The anode consisted of a $50 \mathrm{~nm}$ thin film of Indium-Tin-Oxide (ITO) that was deposited on piranha cleaned glass $18 \times 18 \mathrm{~mm}^{2}$ cover slips through sputtering in an Argon plasma at $1.5 \mathrm{~W} / \mathrm{cm}^{2}$ and $5 \mathrm{mTorr}$. Subsequently, the anode was patterned using photolithography and an $\mathrm{HCl}$ wet etch. Next, a $50 \mathrm{~nm}$-thick layer of amorphous $\mathrm{SiO}_{2}$ was deposited as insulation through sputtering. The oxide layer was then patterned through photolithography and etched using a $\mathrm{CHF}_{3} / \mathrm{O}_{2}$ plasma to define the micro-electrodes. The device consisted of a $500 \times 500 \mu \mathrm{m}^{2}$ opening through the oxide insulation layer with a total area of $0.25 \mathrm{~mm}^{2}$. The thin films on the cover slips were then annealed at $350^{\circ} \mathrm{C}$ in air for $1 \mathrm{hr}$ to provide a sheet resistance of $300 \Omega / \square$ and greater than $85 \%$ transmissivity at wavelengths between $350-700 \mathrm{~nm}$. A $200 \mu \mathrm{m}$ diameter platinum wire and $1 \mathrm{~cm}$ in length served as the cathode.

\section{Reference Electrode}

A reference electrode that consisted of a $200 \mu \mathrm{m}$ in diameter $\mathrm{Ag} / \mathrm{AgCl}$ wire was embedded within the anodic channel as a redox probe. Because the anolyte (basal media) $\mathrm{KCl}$ concentration is only $1 \mathrm{mM}$ (vs. $4 \mathrm{M}$ saturation), the reference electrode's redox potential was calibrated and approximated as $654 \mathrm{mV}$ versus the standard hydrogen electrode potential (vs. SHE).

\section{Electrolytes}

To minimize the cathodic reaction effects, $50 \mathrm{mM}$ potassium ferricyanide was used as an electron sink. The catholyte also contained $20 \mathrm{mM}$ PIPES buffer to maintain the $\mathrm{pH}$ at 7.0 and $1 \mathrm{M} \mathrm{KCl}$ to enhance conductivity.

\section{Assembly}

Figures 3 and 4 depict the geometry and assembled $\mu \mathrm{MFC}$. The anodic and cathodic channels consisted of parallel flow through glass channels. The cathodic channel was fabricated by etching a borosilicate glass microscope slide in $49 \% \mathrm{HF}$ for one hour to create an $18 \mu \mathrm{L}$ volume $(\mathrm{L}=18 \mathrm{~mm}, \mathrm{~W}=2 \mathrm{~mm}, \mathrm{D}=0.5 \mathrm{~mm})$. The anodic channel consisted of a $1 \mu \mathrm{L}$ volume ( $\mathrm{L}=18 \mathrm{~mm}, \mathrm{~W}=2 \mathrm{~mm}, \mathrm{D}=25 \mu \mathrm{m})$ where the depth was defined through a spacer that also served as adhesive sealing foil (Solaronix SX-1170-25) between the microscope slide and the coverslip containing the anode thin film. Lastly, electrical connections and tubing were bonded to the assembly.

\section{Junction}

The sealing foil served as the electrolyte junction between the anode and the cathode. To lower impedance, the channels were filled with media and the foil was allowed to soak overnight resulting in hydration through $1 \mathrm{~mm}$ depth and in an anode-tocathode impedance of $180 \mathrm{k} \Omega$.

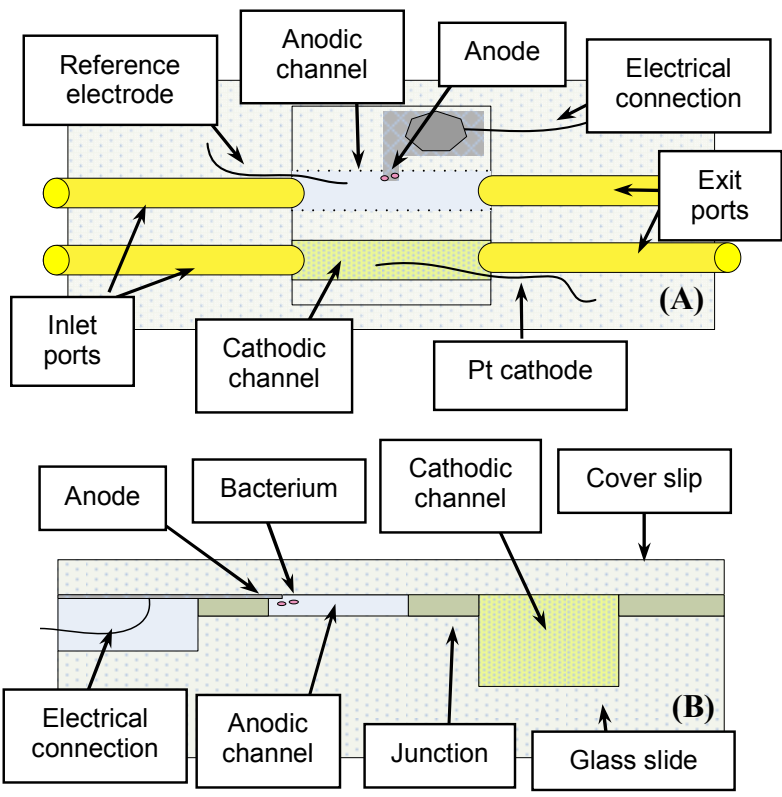

Figure 3. Device was designed to conform to optical microscopy by utilizing transparent materials. A) $\mu \mathrm{MFC}$ top view. B) Cross sectional view.

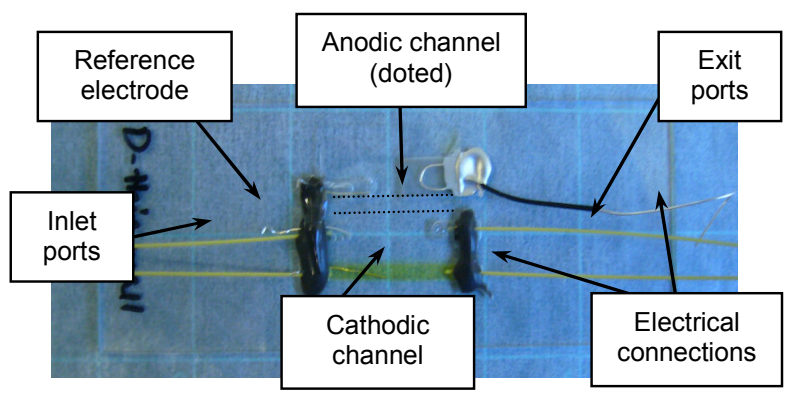

Figure 4. Assembled $\mu \mathrm{MFC}$ image. Anodic and cathodic channels run parallel between inlet and outlet ports. The anodic channel is $2 \mathrm{~mm}$ wide and $25 \mu \mathrm{m}$ high (doted).

\section{EXPERIMENTAL PROCEDURE}

Preliminary experiments in the prototype devices utilize Geobacter sulfurreducens cultured in anaerobic media with fumarate as a final electron acceptor. Prior to testing, the bacteria were $10 \mathrm{x}$ diluted into basal media solution containing $10 \mathrm{mM}$ acetate for 2 hours, and filtered prior to injection into the $\mu \mathrm{MFC}$ so that approximately $10^{4}$ cells were inoculated into the anodic chamber. All the measurements were acquired using a Gamry Reference 600 Potentiostat/Galvanostat/ZRA within a Faraday cage. Images were acquired using a Zeiss inverted fluorescence microscope equipped with a mercury lamp and a Hamamatsu 9100-13 EMCCD camera. 


\section{RESULTS AND DISCUSSION}

Previous studies have shown that $1.4 \mu \mathrm{A} / \mathrm{mm}^{2}$ can be achieved from mature G. sulfurreducens biofilms [2]. However, to determine the signal on a per cell basis, where currents in the hundreds of fA per cell are projected [3,6], background signals and ambient noise must be quantified and minimized. Here we determine the signal to noise ratio (SNR) that can be obtained by characterizing the current output of the cells upon inoculation, after culturing in a soluble electron acceptor, and prior to attachment or adaptation to the anode where the signal is expected to be at its minimum. Because bacteria have yet to attach to the electrode, the electrical signal stems from planktonic biomass intermittently discharging on the electrode.

\section{Bacterium Redox Potential}

The system consists of bacterium within their basal media that contains redox active species such as vitamins and organics. A potential difference between the anode and the cathode of $590 \mathrm{mV}$ was obtained after 30 minutes without microorganisms, which is in agreement to our prior results $[2,3]$. Upon inoculation of the bacterium, a potential change of the anode was detected. As illustrated in Figure 5, the anode reached a steady state redox potential of $318 \mathrm{mV}$ (vs. SHE) for the background media and $239 \mathrm{mV}$ (vs. SHE) after addition of the cells. The latter corresponds well to the redox of cytochrome $c_{o x / r e d}$ proteins $(+250 \mathrm{mV}$ vs. SHE) on the outer membrane. However, this redox is a combined signal from the background and the bacterium suggesting that the membrane cytochromes were reduced.

\section{Electron Transfer}

Of particular interest is the characterization of electron transfer from the biocatalyst to the electrode to maximize current density. An increased metabolic output from bacterium reduces kinetic losses to the electrode and improves fuel cell performance. To determine the signal from the cells, the current from the inoculum and the background were initially measured by poising the anode at $+300 \mathrm{mV}$ (vs. SHE), and the results are presented in Figure 6. The redox potential was chosen to minimize the electron contribution from background species. The steady state currents were measured at $5.0 \mathrm{pA}$ and $0.4 \mathrm{pA}$ for the analytes with and without cells, respectively, resulting in a SNR ratio of 11 for the $0.25 \mathrm{~mm}^{2}$ electrode at $10^{4}$ cells $/ \mu \mathrm{L}$ seeding density. These data, therefore, suggest that G. sulfurreducens per cell electron transfer characterization starting from soluble electron acceptor growth conditions is possible within our system. However, the cells were mobile with stochastic movement upon inoculation and were not resolvable during this study.

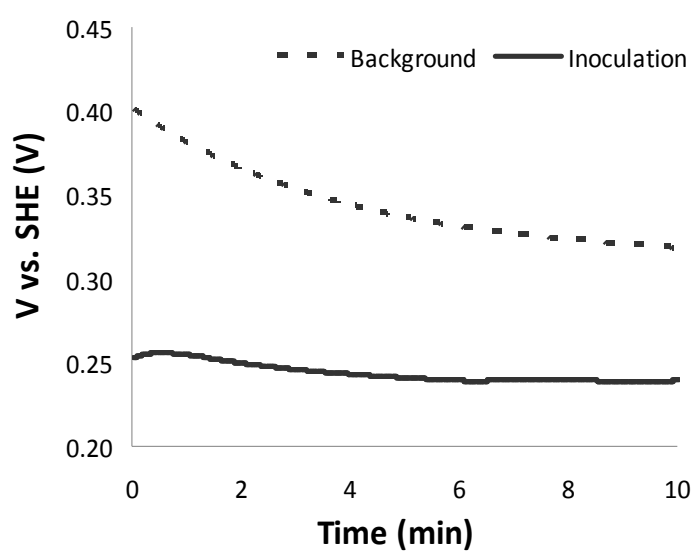

Figure 5. Anode redox potential before and after inoculation of the bacterium. Background potential is due to active redox species such as vitamins. After inoculation, an $80 \mathrm{mV}$ decrease in potential is detected at steady state.

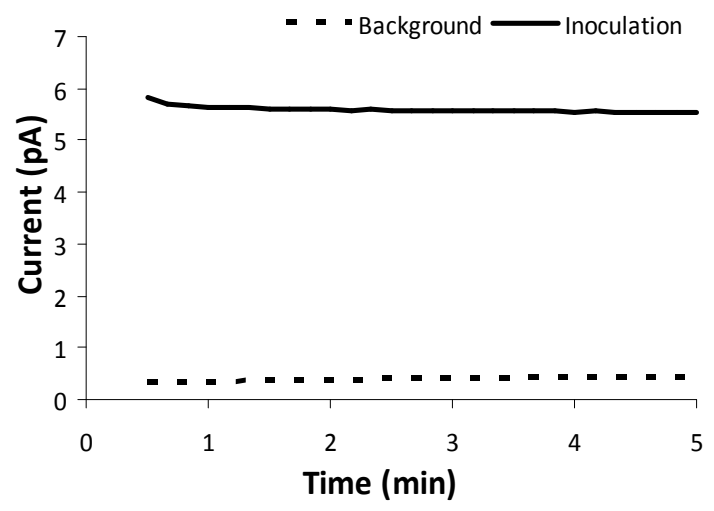

Figure 6. Bacterium electron transfer and background signal at a poised potential of $+300 \mathrm{mV}$ (vs. SHE). Noise is minimized by using the potential comparable to the background media resulting in a SNR of 11 .

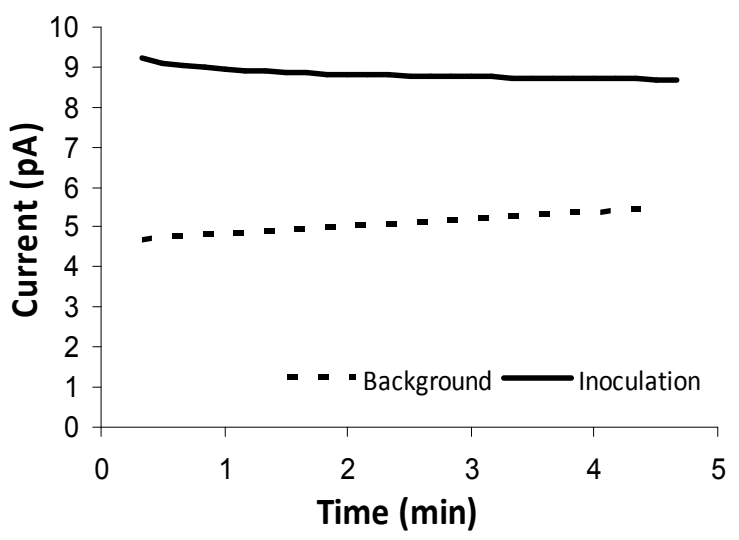

Figure 7. Bacterium electron transfer and background signal at a poised potential of $+400 \mathrm{mV}$ (vs. SHE). Noise is amplified by deviating from the background media potential resulting in a SNR ratio less than 1. 
The SNR for the system, however, was not maintained when obtaining current measurements that deviated from the redox potential of the background. As shown in Figure 7, the SNR is reduced to less than one when the anode is poised at a potential of $+400 \mathrm{mV}$ (vs. SHE). This suggests that an optimal poised potential may be necessary to detect the metabolic signal from the background prior to bacterium physiology adaptation to the anode, which may have biological implications. However, the SNR for a greater range of potentials could be improved by increasing the seeding density upon inoculation, reducing the electrode area, decreasing or eliminating the active species in the background media, and/or allowing time for cell attachment prior to characterization.

\section{Non-Invasive Bacterium Counting}

Strong intrinsic fluorescence, believed to originate from membrane-bound cytochromes involved in the transport of electrons to the extracellular environment, has been reported under UV excitation in a reduced bacterial environment [7]. Figure 8 illustrates the fluorescence of bacterium excited at $350 \mathrm{~nm}$ by a mercury lamp within the microscopy compatible $\mu \mathrm{MFC}$ after one week of culturing. Utilizing this technique, viable cells can be counted accurately as they can be distinguished from nonviable bacterium. In addition, because it is a nondestructive method, culturing can be closely and continuously monitored in situ.

Lastly, to gain further insight on the electrical contribution of bacteria that are not directly in contact with the electrode, our current work involves coupling the intensity of the intrinsic fluorescent cytochromes of $G$. sulfurreducens with its electrical output. This will provide a complete characterization of the discharge of electrons on an electrode by matching optical data with the corresponding electrical signal output.
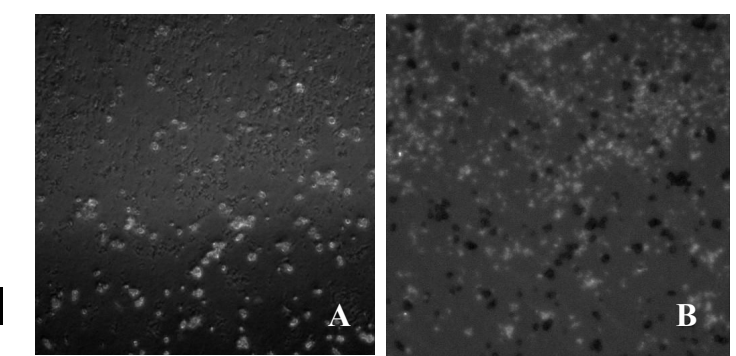

Figure 8. Non-destructive technique that can be used to distinguish viable cells on the electrode to normalize electron transfer to cell count. (A) Phase contrast image at $30 \mathrm{x}$ showing bacterium and bacterial polymer secretions. (B) Viable bacterium intrinsically fluoresce at $350 \mathrm{~nm}$ excitation.

\section{CONCLUSION}

A $\mu \mathrm{MFC}$ on-a-chip system for high resolution characterization of bacterium for energy applications has been developed. A SNR of 11 at a redox potential optimized to reduce background currents was obtained upon inoculation when the bacterium electron transfer is at its lowest. This suggests that characterization of metabolic output to an electrode in a per cell basis is achievable from the presented design. In addition, the device permits extended culturing studies and is compatible with transmission and fluorescence microscopy.

\section{ACKNOWLEDGEMENTS}

We would like to thank the Microfabrication Laboratory staff at UC Berkeley for their continuous support. This work is supported in part by the Sustainable Products and Solutions Program at UC Berkeley.

\section{REFERENCES}

[1]A.M. Makarieva, V.G. Gorshkov, and B. Li, "Energetics of the smallest: do bacteria breathe at the same rate as whales?", Proc. R. Soc. B, 272, 2219-2224, 2005.

[2]E. Parra, and L. Lin "Microbial Fuel Cell based on Electrode-Exoelectrogenic Bacteria Interface", Proceedings of MEMS 2009, January 25-29, 2009.

[3] E.A.Parra, T. Liu, C.R.Buie, J.D. Coates, and L.Lin, "Microfabricated Microbial Fuel Cell for Real-Time BioCatalyst Optical Monitoring and Electrical Signal Coupling", Proceedings of 2nd MFC Conference, Gwangju, Korea, June 10-12, 2009, pp. 191-194.

[4]_M. Chiao, K. Lam, and L. Lin, "Micromachined microbial and photosynthetic fuel cells," JMicromech. and Microeng., Vol. 16, pp. 25472553, Dec. 2006.

[5] C.R. Buie, E.A. Parra, R.D. Sochol, J.D. Coates, and L. Lin, "Characterization of Bacteria for Microbial Fuel Cell Applications Using Dielectrophoresis," in Proceedings of $\mu \mathrm{TAS}$ 2009, Jeju, Korea, November 1-5, 2009.

[6] Esteve-Núñez, A., M.M. Rothermich, M. Sharma, and D.R. Lovley, "Growth of Geobacter sulfurreducens under nutrient-limiting conditions in continuous culture", Environ Microbiol 7(5):641-648, 2005.

[7] Esteve-Núñez, A., J. Sosnik, P. Visconti, and D.R. Lovley, "Fluorescent properties of $c$-type cytochromes reveal their potential role as an extracytoplasmic electron sink in Geobacter sulfurreducens. Environ Microbiol. 10(2):497505, 2008. 